\title{
Antipyretic, anti-inflammatory and analgesic activity of Acacia hydaspica R. Parker and its phytochemical analysis
}

Tayyaba Afsar ${ }^{1 *}$, Muhammad Rashid Khan', Suhail Razak², Shafi Ullah and Bushra Mirza

\begin{abstract}
Background: Inflammation and pain underlies several pathological conditions. Synthetic drugs used for the management of these conditions carry severe toxic effects. Globally efforts are ongoing to introduce novel medicinal plants to develop effective, economic and innocuous drugs. The current study was aimed at investigating the antipyretic, anti-inflammatory and analgesic activity of methanol extract of A. hydaspica aerial parts (AHM) and its active fraction. Furthermore identification and isolation of polyphenolic compounds was carried out to identify the active principles.

Methods: Yeast induced pyrexia, Paw edema, acetic acid-induced writhing and hot plate test were carried out in vivo. HPLC-DAD analysis and combination of different chromatographic techniques, involving vacuum liquid chromatography (VLC) and flash chromatography (FC) were carried out for chemical characterization. The structural heterogeneity of flavanols was characterized by ESI- MS, ${ }^{1} \mathrm{H} N M R,{ }^{13} \mathrm{C}$ NMR and ${ }^{2} \mathrm{D}$ NMR spectroscopic analyses, and also by comparison with reported literature.
\end{abstract}

Results: Oral administration of A. hydaspica methanol extract (AHM) and A. hydaspica ethyl acetate fraction (AHE), showed dose and time dependent decrease in body temperature in yeast induced pyrexia, comparable to standard, Paracetamol. AHM and AHE $(150 \mathrm{mg} / \mathrm{kg})$ significantly $(p<0.001)$ inhibit pain sensation in various pain models, i.e. acetic acid induced writhing and hot plate test. Similarly AHM and AHE demonstrated an anti-inflammatory effect in carrageenan-induced paw edema in rats and $150 \mathrm{mg} / \mathrm{kg}$ dose being distinctly more effective (91.92\% inhibition). When studied on prostaglandin $E_{2}\left(P_{G} E_{2}\right)$ induced edema in rats, $A H M$ and $A H E$ showed maximum inhibition of edema at $150 \mathrm{mg} / \mathrm{kg}$ after $4 \mathrm{~h}$. HPLC chromatogram of AHM revealed the presence of gallic acid, catechin, rutin and caffeic acid. Chromatographic separation and structure characterization of AHE, has led to the identification of three flavan-3-ol derivative including 7-O-galloyl catechin, +catechin and methyl gallate, which have been reported for the first time in A. hydaspica.

Conclusion: These results revealed that the presence of bioactive compounds in $A$. hydaspica might be responsible for the pharmacological activities, confirming the indigenous utility of A. hydaspica against inflammatory disorders.

Keywords: A. hydaspica, Anti-inflammatory, Analgesic, Antipyretic, Flash chromatography

\footnotetext{
* Correspondence: tayyaba_sona@yahoo.com

${ }^{1}$ Department of Biochemistry, Faculty of Biological Sciences, Quaid-i-Azam

University, Islamabad, Pakistan

Full list of author information is available at the end of the article
} 


\section{Background}

For centuries people of developing countries like Pakistan, India and China, rely on traditional medicinal system for the cure of various ailments as substitute health care services due to safety and cost-effectiveness of herbal medications. In different regions of Pakistan local practice of medicinal plants for curing number of diseases is very common. In Pakistan medicinal plants prescribers called Tabib/Hakim use approximately 600-1000 medicinal plants of the country based on their experience, without scientific knowledge for the treatment of wide range of disorders [1]. Certainly local practice of plants is unrestricted in developing countries, but it is obligatory to ascertain the pharmaceutically vital agents responsible for protection against fatal diseases. Currently developed world is also inclined towards complementary and alternative medicines, specifically derived from natural source. At the present, varieties of herbal plants have been extensively used as a curative agent for various infectious diseases globally. It is anticipated that about one quarter of approved modern medicines has been derived from botanicals [2].

Inflammation, pain and pyrexia underlie several pathological conditions. Synthetic drugs, i.e. NSAIDs, opioids and corticosteroids are clinically most important drugs used for the treatment of inflammatory disorders, however their long term use may induce toxic effects including; gastrointestinal ulcers, bleeding, renal disorders etc. $[3,4]$. Globaly efforts are ongoing to introduce novel medicinal plants to develop effective, economic and innocuous drugs [5]. Medicinal plants are believed to be an important source of useful compounds with potential therapeutic effects. The research on plants with apparent folkloric use, as agony relievers, anti-inflammatory agents, should therefore be regarded as a prolific and a rational research strategy in the search for new anti-inflammatory drugs [6].

A. hydaspica R. Parker belongs to family Leguminosae. This species is reported to be common in Iran, India and Pakistan, commonly used as fodder, fuel and wood [7]. It is treated as a synonym of A. eburnea [8]. The bark and seeds are the source of tannins. The plant is locally used as antiseptic. The traditional healers of India use various parts of the plant for the treatment of diarrhea; the leaves and the bark are useful in arresting secretion or bleeding. The pods are helpful in removing catarrhal matter and phlegm from the bronchial tubes. The gum dispels irascibility of the skin and soothes the inflamed membranes of the pharynx, alimentary canal and genito-urinary organs (http://trade.indiamart.com/ details.mp?offer=6763150691). Different species of Acacia were evaluated for their anti-inflammatory, antipyretic and analgesic activities in various animal models. Aqueous extract of the bark of $A$. karroo provided remarkable anti- inflammatory activity against the carrageenan and histamine induced edema and analgesic activity via acetic acid induced writhing model in experimental animals [9]. Bukhari et al. evaluated the analgesic, anti-inflammatory and antiplatelet activities of the methanol extract of A. modesta by using acetic acid, formalin, hot plate and carrageenan induced edema in rodents [10]. Acute (xylene- induced) and chronic (cotton pellet-induced) anti-inflammatory effects of $A$. nilotica have been investigated in rat [11]. Petroleum ether, chloroform and methanol extract of $A$. comigera were evaluated against croton oil induced dermatitis in mice [12]. Ethanol extract of the seeds of A. suma was evaluated against the carrageenan induced hind paw edema in rat model, whereas analgesic activity was evaluated by acetic acid induced writhing and formalin induced linking tests in mice [13]. A. nilotica extract showed inhibitory effect on carrageenan induced paw edema and yeast induced pyrexia in rats [14].

Till date, no pharmacological study has been conducted to evaluate the antipyretic, anti-inflammatory, and analgesic activity of $A$. hydaspica, supporting traditional uses of this plant in folklore medicine. Hence the present study was undertaken to evaluate the antipyretic, anti-inflammatory and analgesic activity of methanol extract and its derived fractions using rat model. Furthermore HPLC finger printing and compounds isolation was performed to identify the active principle compounds responsible for various pharmacological activities.

\section{Methods}

\section{Plant collection}

The aerial parts (bark, twigs, and leaves) of A. hydaspica were collected from Kirpa area Islamabad, Pakistan in the month of April 2011. After identification with the help of relevant literature, voucher specimen (0642531) was assigned and the herbarium specimen was submitted in the Herbarium of Pakistan, Museum of Natural History, Islamabad for future reference.

\section{Extraction}

Shade dried aerial parts (bark, twigs, and leaves) of $A$. hydaspica were ground in to powder $(3 \mathrm{~kg})$ and soaked for 14 days in crude methanol, with occasional shaking. The extract was filtered through filter paper (Whatman filter paper number 45), and concentrated under vacuum using a rotary evaporator (Buchi, R114, Switzerland) at $40^{\circ} \mathrm{C}$ and $472 \mathrm{~g}$ of $A$. hydaspica crude methanol extract (AHM, 15.73\%) was obtained. Partial purification or separation of AHM was done by solvent-solvent extraction. Briefly $12 \mathrm{~g}$ of AHM was suspended in $500 \mathrm{ml}$ distilled water in separating funnel $(1000 \mathrm{ml})$ and successively partitioned with $n$-Hexane, Ethyl-acetate, Chloroform and $n$-Butanol. Each extraction process was repeated three 
times with $500 \mathrm{ml}$ of each solvent, same process was repeated to get enough mass of fractions for various bioactivity testing and chromatographic separation. These solvents with varying polarities theoretically partitioned different plant constituents. The filtrate was concentrated using rotary evaporator and weighed to determine the resultant mass. After this initial partitioning we got four soluble fractions; $A$. hydaspica $n$-hexane fraction (AHH, $5.27 \%$ yield), A. hydaspica ethyl acetate fraction (AHE, 27.77\% yield), A. hydaspica chloroform fraction (AHC, $1.94 \%$ yield), $A$. hydaspica $n$-butanol fraction (AHB, $41.66 \%$ yield) and remaining aqueous fraction (AHA, $8.05 \%$ yield). The AHE showed to be the most active fraction and $\mathrm{AHH}, \mathrm{AHC}$, AHB and AHA fractions were not found active in any of the assays carried out in this study. AHM was subjected to High Performance Liquid Chromatography (HPLC) for compound fingerprinting and AHE was subjected to chromatographic isolation for further fractionation and purification of polyphenolics.

\section{Compositional analysis by HPLC}

HPLC analysis of AHM was carried out by using HPLCDAD (Agilent Germany) equipment using Sorbex RXC8 (Agilent USA) analytical column with $5 \mu \mathrm{m}$ particle size. Mobile phase consisted of eluent A, (acetonitrilemethanol-water-acetic acid /5: 10: 85: 1) and eluent B (acetonitrile-methanol-acetic acid/40: 60: 1). The gradient (A: B) utilized was the following: $0-20 \mathrm{~min}$ (0 to $50 \% \mathrm{~B}$ ), $20-25 \mathrm{~min}$ (50 to $100 \% \mathrm{~B}$ ), and then isocratic $100 \% \mathrm{~B}(25-40 \mathrm{~min})$ at flow rate of $1 \mathrm{ml} / \mathrm{min}$, and injection volume was $20 \mu \mathrm{l}$. Rutin and Gallic acid were analyzed at $257 \mathrm{~nm}$, catechin and apigenin at $279 \mathrm{~nm}$, caffeic acid at $325 \mathrm{~nm}$ and quercitin, myricetin, kaempherol were analyzed at $368 \mathrm{~nm}$. Every time column was reconditioned for $10 \mathrm{~min}$ before the next analysis. All samples were assayed in triplicate. Quantification was carried out by the integration of the peak using the external standard method. All chromatographic operations were carried out at ambient temperature.

\section{Isolation of compounds}

The scheme of fractionation and isolation is explained in flow chart (Figure 1). Briefly $10 \mathrm{~g}$ of $A$. hydaspica ethyl acetate fraction (AHE) was dissolved in DCM (Dichloromethane), mixed with neutral acid wash (super cell NF) and dried down completely with rotavap. Dried extract sample was loaded on silica gel using glass column packed with silica (200-400 mesh), attached with vacuum line source (vacuum liquid chromatography, VLC). The column was eluted with dichloromethane (DCM), then DCM-methanol mixture in increasing order of polarity and 10 fractions were collected $(1 \mathrm{~L}$ each), and three major phenolic fractions (VLC-AHE/F4-F6) selected on the basis of TLC (silica gel $60 \mathrm{~F}_{254}$ plates,
MERCK) and ${ }^{1}$ HNMR spectra similarity, and were combined, and subjected to flash liquid chromatography, carried on Combi-flash Teledyne ISCO using silica and column eluted with mixture of DCM: Methanol in increasing order of polarity. Spectra were monitored at all wavelengths (200 nm-780 nm) with Peak width 2 min, and Thresh hold 0.02 AU. 146 fractions collected with ISCO were pooled into 27 fractions according to their TLC and ISCO chromatogram spectral peaks. ${ }^{1}$ HNMR of ISCO fractions indicated the presence of chromatographically pure compounds IF 9 (C1), IF7 (C2) and IF3 (C3); Structures of isolated compounds were determined by NMR assignments.

\section{Nuclear magnetic resonance spectroscopy (NMR)}

${ }^{1} \mathrm{H}$ - and ${ }^{13} \mathrm{C}$-NMR spectrum for all compounds was recorded on a CDD NMR instrument: Varian $600 \mathrm{MHz}$ $\left({ }^{1} \mathrm{H}\right.$ and ${ }^{13} \mathrm{C}$ frequencies of 599.664 and $150.785 \mathrm{MHz}$, respectively) at $25^{\circ} \mathrm{C}$. Spectra of all compounds were obtained in Methanol-d4 and DMSO-d6. Conventional 1D and 2D Fourier transform techniques were employed as necessary to achieve unequivocal signal assignments and structure proof for all compounds independently. Stereo-chemical assignments were made with ROESY and NOESY experiments. Detailed analysis of resolution enhanced spectra (Peak picking, integration and multiplet analysis) was performed using Varian NMR and ACD/ NMR processor, Academic Edition. The NMR spectra and chemical shifts of isolated compounds were compared with published data.

\section{Animals}

Sprague Dawley rats (180-220 g) of either sex, maintained at primate facility Quaid-i-Azam University Islamabad, Pakistan were used for the study. Animals were kept at standard conditions of temperature $\left(25 \pm 1^{\circ} \mathrm{C}\right)$ and $12 / 12 \mathrm{~h}$ light/dark cycle, have free access to standard laboratory feed and water. All experimental procedures involving animals were conducted in accordance with the guidelines of the National Institutes of Health (NIH guidelines). The study protocols were approved by Ethical committee of Quaid-i-Azam University Islamabad. Six animals were used in each group. Experiments on animals were performed in accordance with the guidelines of the institute of animal ethical committee, NIH, Islamabad.

\section{Acute toxicity study}

The acute toxicity studies were conducted as per the guidelines 425 of Organization for Economic Cooperation and Development (OECD) for testing of chemicals for acute oral toxicity [15]. Rats $(n=6)$ of either sex treated with different doses (50, 250, 500, 1000, 2000 and $3000 \mathrm{mg} / \mathrm{kg}$, p.o.), while the control group received saline $(10 \mathrm{ml} / \mathrm{kg})$. All the groups were observed up to $6 \mathrm{~h}$ for any 


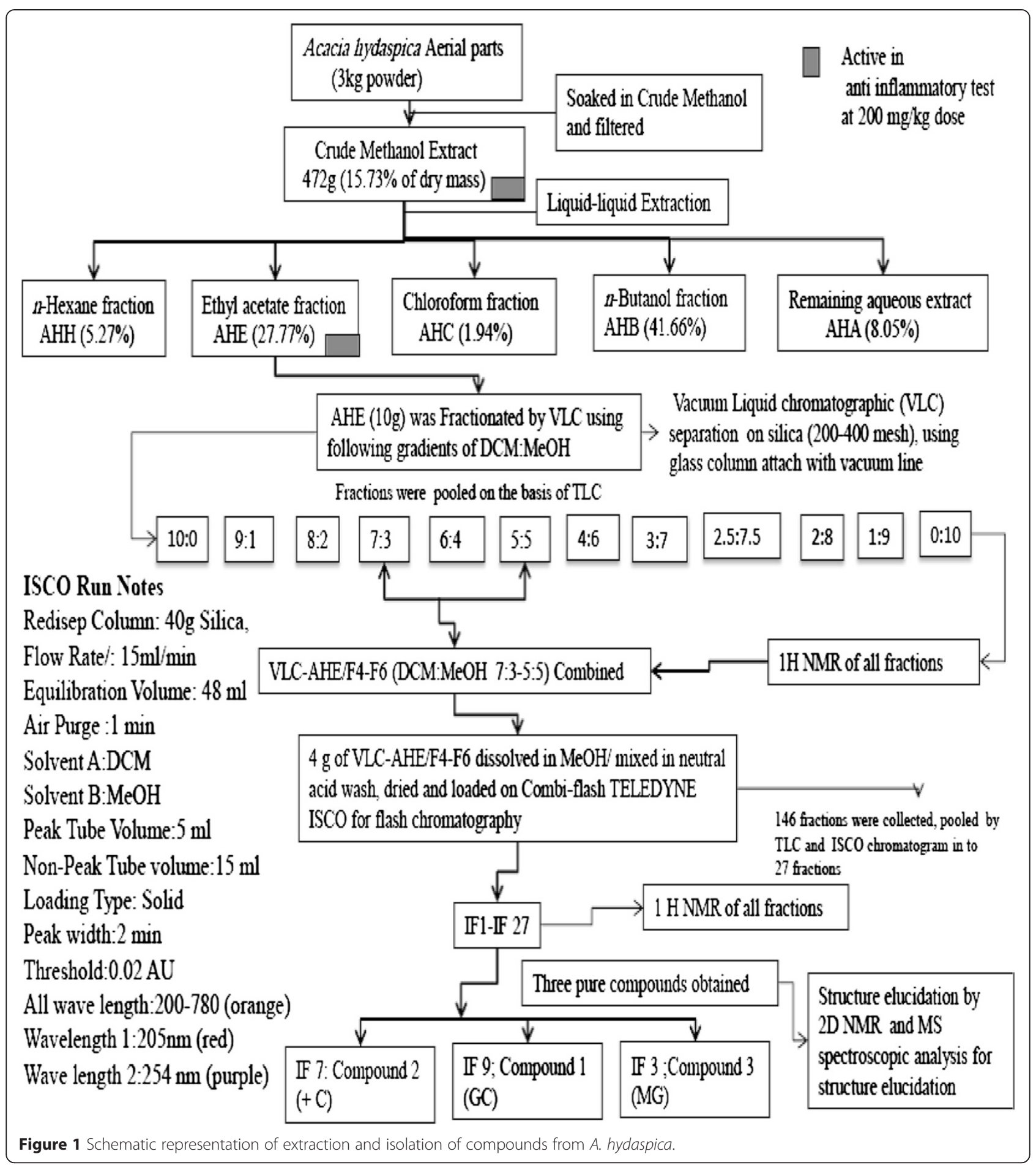

gross effect and then mortality rate was observed after $24 \mathrm{~h}$ of treatment.

\section{Pharmacological activities}

Antipyretic activity

The antipyretic activity of AHM and its active fraction AHE was evaluated using Sprague Dawley rats (180-220 g) of either sex using previously explained method [16]. The selected animals were healthy and normal body temperature of each rat was checked by using digital thermometer. Pyrexia was induced in all rats by injection of $20 \%$ aqueous suspension of brewer's yeast (Saccharomyces cerevisiae) $10 \mathrm{ml} / \mathrm{kg}$. Subcutaneous (SC). All animal groups (6/group) were fasted with access to only water, 
after injection of yeast for $24 \mathrm{~h}$. After that, the rectal temperature of each rat was recorded and pyrexia was confirmed by increase in temperature more than $1^{\circ} \mathrm{C}$, while animals showing less than $1^{\circ} \mathrm{C}$ rise in temperature were excluded from the experiment. The group I received saline $(10 \mathrm{ml} / \mathrm{kg})$, group II received paracetamol $(100 \mathrm{mg} / \mathrm{kg})$ as a standard drug, while group III-XII received 50, 100 and $150 \mathrm{mg} / \mathrm{kg}$, p.o. doses (through feeding tubes) of AHM and AHE respectively. The rectal temperature of the groups was recorded at $1 \mathrm{~h}$ intervals for $5 \mathrm{~h}$.

\section{Anti-inflammatory activity}

Carrageenan induced paw edema The anti-inflammatory activity was performed on rat of either sex (180-220 g). The normal paw volumes of all the rats were measured ab initio and animals were divided into different groups, each consisting of six rats [1]. The group I was treated with normal saline (10 ml/kg, i.p.), Group II, III and IV with the standard drugs i.e. diclofenac sodium, aspirin and fluoxetine $(10 \mathrm{mg} / \mathrm{kg})$ respectively while rest of the groups were treated with AHM and AHE (50, 100 and $150 \mathrm{mg} / \mathrm{kg}$, p.o.). After thirty minutes of the above intra-peritoneal and oral administration, carrageenan $(1 \%, 0.1 \mathrm{ml})$ was given subcutaneously into the sub plantar tissue of the right hind paw of each rat. The paw volume was quantified using digital plethysmometer before and at $1^{\text {st }}, 2^{\text {nd }}, 3^{\text {rd }}$ and $4^{\text {th }} \mathrm{h}$ after carrageenan administration. The edema volume of paw and percent inhibition of edema were calculated using the following formulae:

$$
\mathrm{EV}=\mathrm{PVA}-\mathrm{PVI}
$$

$\mathrm{EV}$ = edema volume, $\mathrm{PVI}=$ Paw volume before carrageenan administration (i.e. initial paw volume) and, PVA = Paw volume after carrageenan administration.

$$
\text { Percent inhibition }=\left[\frac{\mathrm{EVc}-\mathrm{EVt})}{\mathrm{EVc}} \times 100\right]
$$

$\mathrm{EVc}=\mathrm{Edema}$ volume of control animals, $\mathrm{EVt}=\mathrm{Edema}$ volume of test drug animals.

Prostaglandin $\mathrm{E}_{2}$-induced paw edema Rats of either sex were divided into different groups $(\mathrm{n}=6)$ and treated intraperitoneal with saline (control), Diclofenac Sodium $(10 \mathrm{mg} / \mathrm{kg}$, i.p., reference standard), AHM and AHE (50, 100 and $150 \mathrm{mg} / \mathrm{kg}$ orally). After $30 \mathrm{~min}$ of treatment, $100 \mu \mathrm{l}$ of prostaglandin $\mathrm{E}_{2}(0.01 \mu \mathrm{l} / \mathrm{ml})$ was administered into the sub planter side of right hind paw of each rat, and the edema size was determined as aforesaid [17].

\section{Analgesic activity}

Acetic acid induced writhing test The method used in this test has previously been described by khan et al. [18]. Total number of writhing movements following i.p. administration of acetic acid solution $(10 \mathrm{ml} / \mathrm{kg}, 1 \%)$ was recorded over a period of $10 \mathrm{~min}$, starting $5 \mathrm{~min}$ after acetic acid injection. Rats were treated with AHM and AHE (50, 100 and $150 \mathrm{mg} / \mathrm{kg}$ ), vehicle (saline), standard drugs (diclofenac sodium and aspirin $10 \mathrm{mg} / \mathrm{kg}$ ), $30 \mathrm{~min}$ before acetic acid injection [19]. The numbers of writhings movements (Constriction of abdominal muscles along with the stretching of hind limbs) were counted in both untreated and treatment groups and percentage inhibition in abdominal writhings was calculated as follow.

$$
\% \text { inhibition of abdominal writhing }=\left[\frac{\mathrm{Wc}-\mathrm{Wt})}{\mathrm{Wc}} \times 100\right] \text {, }
$$

$\mathrm{W}=$ No. of writhing, $\mathrm{c}=$ Control, and $\mathrm{t}=$ Test.

Hot plate test The procedure described by Muhammad et al. [1], was followed to perform this test. Sprague Dawley rats of either sex $(n=6)$ weighing $180-220$ g were used. Animals were subjected to pre-testing on a hot plate (Harvard apparatus) maintained at $55 \pm 0.1^{\circ} \mathrm{C}$. Animals having latency time greater than $15 \mathrm{sec}$ on hot plate during pre-testing were excluded. Animals were divided randomly into 5 groups, each containing of six rats. The group I was treated with saline $(10 \mathrm{ml} / \mathrm{kg})$, group II and III with diclofenac sodium and fluoxetine $(10 \mathrm{mg} / \mathrm{kg}$, i.p.), and Group IV-IX were treated with oral doses of 50, 100 and $150 \mathrm{mg} / \mathrm{kg}$ of AHM and AHE respectively. Diclofenac sodium and fluoxetine were used as reference drugs for comparison $[19,20]$. After 30 min of dose administration, rats were dropped inside the cylinder onto the hot plate and the latency time (time for which rat remains on the hot plate without licking or flicking of hind limb or jumping) was recorded in seconds. In order to prevent the tissue damage the cut off time of $30 \mathrm{sec}$ was set for all animals. The latency time was recorded for each group at 0 , 30, 60, 90 and 120 min following drug administration. Percent analgesia was calculated using the following formula.

$$
\% \text { Analgesia }=\left[\frac{(\text { Test latency }- \text { control latency })}{(\text { Cut off time-control latency })} \times 100\right]
$$

\section{Statistical analysis}

All values were expressed as mean \pm SEM and data were analyzed by Graph pad using One-way analysis of variance followed by Tukey's multiple comparison test and Two-way analysis of variance (ANOVA) followed by Bonferroni multiple comparison test. $p<0.05$ was considered significant.

\section{Results}

\section{Estimation of acute toxicity}

AHM and AHE found safe at all tested doses (up to $3000 \mathrm{mg} / \mathrm{kg}$ ) and did not show any noxious symptom in 
rats like sedation, convulsions, diarrhea, and irritation. During the $48 \mathrm{~h}$ assessment, no mortality was found.

\section{Antipyretic activity}

The AHM and AHE significantly $(p<0.001)$ attenuated hyperthermia in rats. The mean increase in rectal temperature recorded after $24 \mathrm{~h}$ of yeast injection, was $2{ }^{\circ} \mathrm{C}-2.43^{\circ} \mathrm{C}$. The inhibition was dose dependent and remained significant up to $5 \mathrm{~h}$ of administration. AHE $150 \mathrm{mg} / \mathrm{kg}$ dose showed the maximum antipyretic effect and return body temperature to normal levels $(p>0.05)$ more efficiently than standard drug paracetamol (Table 1).

\section{Anti-inflammatory activity}

\section{Carrageenan induced paw edema}

In the carrageenan-induced edema, crude extract of $A$. hydaspica (AHM) and its fraction (AHE), induced a dose and time dependent reduction in paw edema. The antiinflammatory activity became significant $(p<0.05), 2 \mathrm{~h}$ after carrageenan injection by $150 \mathrm{mg} / \mathrm{kg}$ dose whilst; maximum inhibition was observed after $4 \mathrm{~h}$. The percent inhibition of inflammation by AHM $(150 \mathrm{mg} / \mathrm{kg})$ was more pronounced than aspirin, whilst the inflammatory activity revealed by diclofenac sodium was non-significantly different from AHM (Table 2).

\section{Prostaglandin induced paw edema}

AHM and AHE revealed a dose dependent $(50-15 \mathrm{mg} / \mathrm{kg})$ and time dependent reduction in prostaglandin $\mathrm{E}_{2}\left(\mathrm{PGE}_{2}\right)$ induced paw edema in rats. Reversal of edema starts $2 \mathrm{~h}$ after the injection of $\mathrm{PGE}_{2}$, and peak inhibition was seen after $4 \mathrm{~h}$. The AHE induced anti-inflammatory activity comparable to standard reference drug (Table 3).

\section{Peripheral analgesic effect}

Acetic acid induced writhing test

Results showed that AHM and its derived fraction AHE significantly $(p<0.001)$ and dose dependently $(50,100$ and $150 \mathrm{mg} / \mathrm{kg}$ ), reduced the number of abdominal constriction induced by administration of $1 \%$ acetic acid solution. The inhibitory effect of Diclofenac sodium was non-significantly different from the protective effect revealed by AHM and AHE (100-150 $\mathrm{mg} / \mathrm{kg}$ dose) (Table 4).

\section{Central analgesic effect \\ Hot plate method (Thermal stimulation)}

In this assay $A$. hydaspica methanol extract (AHM) and its ethyl acetate fraction (AHE) exhibited a dose dependent increase in latency time and inhibited pain sensation in a pattern similar to standard drug; diclofenac sodium whilst the effect of both AHM and AHE, was shown to be more pronounced than fluoxetine at $150 \mathrm{mg} / \mathrm{kg}$ dose (Figure 2, Table 5).

\section{HPLC analysis}

To establish the fingerprint chromatogram for AHM, Gallic acid, catechins, caffeic acid, rutin, apigenin, kaempferol, myricetin and quercetin were used as markers. HPLC chromatogram revealed the presence of gallic acid, catechin, caffeic acid, and rutin by comparison with retention time and UV absorbance of purified standards. The relative amounts of the four phenolic compounds found in AHM were in the order of catechin $(558.9 \mu \mathrm{g} / 100 \mathrm{mg}$ dry sample) $>$ Gallic acid $(300.051 \mu \mathrm{g} / 100 \mathrm{mg}$ dry sample $)>$ rutin $(235.38 \mu \mathrm{g} / 100 \mathrm{mg}$ dry sample $)>$ caffeic acid (137.43 $\mu \mathrm{g} / 100 \mathrm{mg}$ dry sample), respectively (Figure 3).

\section{Phytochemistry of AHE}

The ethyl-acetate fraction of A. hydaspica methanol extract was fractionated by VLC chromatography and ISCO flash chromatography to afford several enriched fractions and three pure compounds $\mathrm{C} 1, \mathrm{C} 2$ and $\mathrm{C} 3$. Isolated compounds were identified as 7-O-galloyl catechin (C1), catechin (C2) [20,21] and methyl gallate (C3) [22] by comparison of their $1 \mathrm{D}$ and $2 \mathrm{D}$ NMR spectral data

Table 1 Effect of AHM and its fraction on brewer's yeast-induced pyrexia

\begin{tabular}{|c|c|c|c|c|c|c|c|c|}
\hline \multirow[t]{3}{*}{ Treatment } & \multirow[t]{3}{*}{ Dose mg/kg } & \multirow{3}{*}{$\begin{array}{l}\text { Body } \\
\text { temp. (N) }\end{array}$} & \multicolumn{6}{|c|}{ Rectal temperature $\left({ }^{\circ} \mathrm{C}\right)$} \\
\hline & & & \multicolumn{6}{|c|}{ After administration of drug } \\
\hline & & & After 24 h (T) & $1 \mathrm{~h}(\mathrm{P} 1)$ & $2 \mathrm{~h}(\mathrm{P} 2)$ & $3 \mathrm{~h}(\mathrm{P} 3)$ & $4 \mathrm{~h}(\mathrm{P} 4)$ & 5 h (P5) \\
\hline Saline & $10 \mathrm{ml}$ & $36.96 \pm 0.21$ & $38.96 \pm 0.02$ & $38.88 \pm 0.09$ & $38.73 \pm 0.03$ & $38.62 \pm 0.02$ & $38.55 \pm 0.06$ & $38.5 \pm 0.014$ \\
\hline Paracetamol & 100 & $37.36 \pm 0.25$ & $39.35 \pm 0.21$ & $38.70 \pm 0.27$ & $37.99 \pm 0.07^{*}$ & $37.79 \pm 0.04^{*}$ & $37.49 \pm 0.02^{* *}$ & $37.395 \pm 0.02^{* * *}$ \\
\hline \multirow[t]{3}{*}{ AHM } & 50 & $37.23 \pm 0.12$ & $39.03 \pm 0.06$ & $39.32 \pm 0.12$ & $38.47 \pm 0.084$ & $38.15 \pm 0.05$ & $37.91 \pm 0.03$ & $37.77 \pm 0.14$ \\
\hline & 100 & $36.85 \pm 0.05$ & $39.17 \pm 0.08$ & $39.05 \pm 0.08$ & $38.12 \pm 0.021$ & $37.94 \pm 0.06$ & $37.76 \pm 0.05^{*}$ & $37.12 \pm 0.03^{* * *}$ \\
\hline & 150 & $37.30 \pm 0.1$ & $39.53 \pm 0.18$ & $39.20 \pm 0.14$ & $38.05 \pm 0.09^{* * *}$ & $37.86 \pm 0.04^{* * *}$ & $37.62 \pm 0.03^{*}$ & $37.36 \pm 0.06^{* * *}$ \\
\hline \multirow[t]{3}{*}{ AHE } & 50 & $37.19 \pm 0.10$ & $39.43 \pm 0.54$ & $38.82 \pm 0.41$ & $38.01 \pm 0.014$ & $37.99 \pm 0.01$ & $37.68 \pm 0.045^{*}$ & $37.24 \pm 0.239^{* * *}$ \\
\hline & 100 & $36.85 \pm 0.05$ & $38.67 \pm 0.44$ & $38.6 \pm 0.489$ & $37.88 \pm 0.03^{*}$ & $37.475 \pm 0.324^{* *}$ & $37.31 \pm 0.19^{* * *}$ & $36.75 \pm 0.245^{* * *}$ \\
\hline & 150 & $37.10 \pm 0.10$ & $39.18 \pm 0.28$ & $38.55 \pm 0.45$ & $37.62 \pm 0.02^{* *}$ & $37.625 \pm 0.494^{* *}$ & $37.195 \pm 0.005^{* * *}$ & $37.13 \pm 0.12^{* * *}$ \\
\hline
\end{tabular}

Data values shown represent mean \pm SEM $(n=6) .{ }^{*} p<0.05,{ }^{* *} p<0.01,{ }^{* * *} p<0.001$ versus only brewer's yeast treated group (Two-way ANOVA followed by Bonferroni multiple comparison test). $\mathrm{N}$ indicates mean body temperature before pyrexia. 
Table 2 Effect of AHM and its fraction on carrageenan-induced paw edema in rats

\begin{tabular}{|c|c|c|c|c|c|c|}
\hline \multirow[t]{2}{*}{ Treatment } & \multirow[t]{2}{*}{ Dose/route } & \multirow{2}{*}{$\begin{array}{l}\text { Mean paw } \\
\text { volume before } \\
\text { carrageenan } \\
\text { injection }\end{array}$} & \multicolumn{4}{|c|}{$\begin{array}{l}\text { Increase in paw volume }(\mathrm{ml}) \text { after carrageenan injection (mean } \pm \text { SEM)/Percent } \\
\text { inhibition of edema }\end{array}$} \\
\hline & & & $+1 \mathrm{~h}$ & $+2 \mathrm{~h}$ & $+3 h$ & $+4 \mathrm{~h}$ \\
\hline Saline & $2 \mathrm{ml}$, i.p. & $1.2 \pm 0.0265$ & $2.66 \pm 0.015$ & $2.5 \pm 0.095$ & $2.24 \pm 0.104$ & $1.93 \pm 0.053$ \\
\hline \multirow[t]{6}{*}{ AHM } & 50 mg/kg, p.o. & $1.043 \pm 0.03$ & $2.488 \pm 0.045$ & $1.82 \pm 0.062$ & $1.56 \pm 0.047$ & $1.39 \pm 0.032$ \\
\hline & & & $(1.34 \pm 0.917)$ & $(40.23 \pm 0.413)$ & $(52.29 \pm 3.12)$ & $(52.46 \pm 2.419)$ \\
\hline & 100 mg/kg, p.o. & $0.89 \pm 0.04$ & $2.311 \pm 0.03$ & $1.543 \pm 0.02$ & $1.301 \pm 0.015$ & $1.156 \pm 0.05$ \\
\hline & & & $(3.11 \pm 1.6)$ & $(49.41 \pm 2.023)$ & $\left(60.47 \pm 0.429^{*}\right)$ & $\left(63.47 \pm 0.457^{*}\right)$ \\
\hline & 150 mg/kg, p.o. & $1.01 \pm 0.037$ & $2.423 \pm 0.043$ & $1.49 \pm 0.07$ & $1.27 \pm 0.060$ & $1.119 \pm 0.06$ \\
\hline & & & $(3.63 \pm 1.135)$ & $\left(63.07 \pm 0.09^{*}\right)$ & $\left(75 \pm 0.23^{* *}\right)$ & $\left(85.06 \pm 1.47^{* *}\right)$ \\
\hline \multirow[t]{6}{*}{ AHE } & 50 mg/kg, p.o. & $1.05 \pm 0.05$ & $2.473 \pm 0.013$ & $1.797 \pm 0.039$ & $1.473 \pm 0.046$ & $1.343 \pm 0.029$ \\
\hline & & & $(2.295 \pm 0.10)$ & $\left(46.64 \pm 0.63^{* * *}\right)$ & $\left(69.56 \pm 0.564^{* * *}\right)$ & $\left(78.29 \pm 1.000^{* * *}\right)$ \\
\hline & 100 mg/kg, p.o. & $1.01 \pm 0.29$ & $2.307 \pm 0.036$ & $1.491 \pm 0.010$ & $1.274 \pm 0.37$ & $1.09 \pm 0.51$ \\
\hline & & & $(2.50 \pm 0.20)$ & $\left(67.14 \pm 0.500^{* * *}\right)$ & $\left(81.159 \pm 0.5^{* * *}\right)$ & $\left(92.07 \pm 1.00^{* * *}\right)$ \\
\hline & 150 mg/kg, p.o. & $1.01 \pm 0.5$ & $2.403 \pm 0.05$ & $1.46 \pm 0.026$ & $1.178 \pm 0.019$ & $1.036 \pm 0.036$ \\
\hline & & & $(3.86 \pm 0.428)$ & $\left(67.85 \pm 1.00^{* * *}\right)$ & $\left(87.82 \pm 1.00^{* * *}\right)$ & $\left(93.40 \pm 1.00^{* * *}\right)$ \\
\hline \multirow[t]{2}{*}{ Diclofenac sodium } & 10 mg/kg, i.p. & $1.19 \pm 0.015$ & $2.576 \pm 0.03$ & $1.600 \pm 0.02$ & $1.426 \pm 0.0305$ & $1.27 \pm 0.01$ \\
\hline & & & $(5.52 \pm 0.575)$ & $\left(68.46 \pm 0.815^{* *}\right)$ & $\left(77.24 \pm 0.192^{* *}\right)$ & $\left(89.04 \pm 2.048^{* * *}\right)$ \\
\hline \multirow[t]{2}{*}{ Fluoxetine } & 10 mg/kg, i.p. & $1.09 \pm 0.064$ & $2.50 \pm 0.091$ & $1.63 \pm 0.04$ & $1.343 \pm 0.055$ & $1.192 \pm 0.017$ \\
\hline & & & $(3.86 \pm 0.212)$ & $\left(58.461 \pm 1.972^{*}\right)$ & $\left(75.64 \pm 0.093^{* *}\right)$ & $\left(85.98 \pm 2.008^{* *}\right)$ \\
\hline \multirow[t]{2}{*}{ Aspirin } & 10 mg/kg, i.p. & $1.157 \pm 0.04$ & $2.597 \pm 0.032$ & $1.736 \pm 0.075$ & $1.486 \pm 0.066$ & $1.34 \pm 0.0264$ \\
\hline & & & $(1.84 \pm 0.50)$ & $\left(55.46 \pm 0.246^{*}\right)$ & $\left(68.30 \pm 0.094^{* *}\right)$ & $\left(74.93 \pm 5.15^{* *}\right)$ \\
\hline
\end{tabular}

Data values shown represent mean \pm SEM $(\mathrm{n}=6)$. ${ }^{*} p<0.05,{ }^{* *} p<0.01,{ }^{* * *} p<0.001$ versus only carrageenan treated group (Two-way ANOVA followed by Bonferroni multiple comparison test). Percentage inhibition is shown in brackets. Inhibition in saline treated group at each time point was calculated relative to paw edema after $1 \mathrm{~h}$.

with the reported data in the literature. Figure 4 has shown the structure of isolated flavanols from AHE. A. hydaspica ethyl-acetate extract (AHE) yields $187.5 \mathrm{mg} / \mathrm{g}$ of Compound 1, $100 \mathrm{mg} / \mathrm{g}$ of Compound 2 and $37.5 \mathrm{mg} / \mathrm{g}$ of Compound 3 (Figure 4).

\section{Discussion}

To the best of our knowledge this is the first report on antipyretic, analgesic and anti- inflammatory activities of A. hydaspica methanol extract of arial parts and its derived ethyl acetate fraction (AHE). Present investigation showed that the AHM and AHE possess noticeable antipyretic, analgesic and anti-inflammatory properties with a reasonable protection profile.

HPLC analysis of AHM extract shows the presence of bioflavonoids, Gallic acid, catechin, caffeic acid and rutin, which were identified for the first time in subject plant. Furthermore chemical investigation of AHE resulted in isolation of 7-O-galloyl catechin, +catechin and methyl gallate.

Gallic acid revealed anti-inflammatory activity by interfering with the functioning of polymorphonuclear

Table 3 Effect of AHM and its fraction on prostaglandin $E_{2}$-induced paw edema in rats

\begin{tabular}{|c|c|c|c|c|c|}
\hline \multirow[t]{2}{*}{ Treatment } & \multirow[t]{2}{*}{ Dose/route } & \multicolumn{4}{|c|}{ Percent inhibition of edema Volume } \\
\hline & & $+1 \mathrm{~h}$ & $+2 \mathrm{~h}$ & $+3 \mathrm{~h}$ & $+4 \mathrm{~h}$ \\
\hline \multirow[t]{3}{*}{ AHM } & 50 mg/kg, p.o. & $2.44 \pm 0.29$ & $18.58 \pm 1.744^{* * *}$ & $52.25 \pm 1.52^{* * *}$ & $54.186 \pm 3.13^{* * *}$ \\
\hline & 100 mg/kg, p.o. & $3.76 \pm 0.176$ & $33.31 \pm 1.084^{* * *}$ & $72.86 \pm 2.081^{* * *}$ & $75.19 \pm 2.62^{* * *}$ \\
\hline & 150 mg/kg, p.o. & $4.16 \pm 0.176$ & $42.50 \pm 1.76^{* * *}$ & $86.72 \pm 3.45^{* * *}$ & $86.11 \pm 1.41^{* * *}$ \\
\hline \multirow[t]{3}{*}{ AHE } & 50 mg/kg, p.o. & $4.72 \pm 0.355$ & $24.16 \pm 1.20^{* * *}$ & $64.34 \pm 1.88^{* * *}$ & $75.68 \pm 2.61^{* * *}$ \\
\hline & 100 mg/kg, p.o. & $4.33 \pm 0.12$ & $37.77 \pm 1.36^{* * *}$ & $77.21 \pm 2.23^{* * *}$ & $84.12 \pm 0.90^{* * *}$ \\
\hline & 150 mg/kg, p.o. & $4.80 \pm 0.152$ & $59.338 \pm 3.05^{* * *}$ & $90.57 \pm 0.76^{* * *}$ & $91.345 \pm 0.57^{* * *}$ \\
\hline Diclofenac sodium & 10 mg/kg, i.p. & $5.13 \pm 0.145$ & $55.83 \pm 2.63^{* * *}$ & $87.72 \pm 2.53^{* * *}$ & $88.11 \pm 0.68^{* * *}$ \\
\hline
\end{tabular}


Table 4 Effect of AHM and its fraction on acetic acid induced writhing

\begin{tabular}{llll}
\hline Groups & $\begin{array}{l}\text { Drug (dose), } \\
\text { route }\end{array}$ & $\begin{array}{l}\text { No. of writhing } \\
\text { (mean } \pm \text { SEM) }\end{array}$ & \% inhibition \\
\hline Saline & $10 \mathrm{ml} / \mathrm{kg}$ & $70.38 \pm 2.7$ & 0 \\
AHM & $50 \mathrm{mg} / \mathrm{kg}$, p.o. & $27.65 \pm 1.005^{* * *}$ & $60.71 \pm 0.66$ \\
& $100 \mathrm{mg} / \mathrm{kg}$, p.o. & $18.09 \pm 1.24^{* * *}$ & $74.29 \pm 1.20$ \\
& $150 \mathrm{mg} / \mathrm{kg}$, p.o. & $16.15 \pm 1.175^{* * *}$ & $77.05 \pm 1.70$ \\
AHE & $50 \mathrm{mg} / \mathrm{kg}$, p.o. & $18.25 \pm 1.25^{* * *}$ & $74.06 \pm 1.15$ \\
& $100 \mathrm{mg} / \mathrm{kg}$, p.o. & $15.00 \pm 1.00^{* * *}$ & $78.68 \pm 1.05$ \\
& $150 \mathrm{mg} / \mathrm{kg}$, p.o. & $12.75 \pm 1.25^{* * *}$ & $81.88 \pm 0.05$ \\
Diclofenac sodium & $10 \mathrm{mg} / \mathrm{kg}$, i.p. & $13.22 \pm 1.89^{* * *}$ & $81.65 \pm 1.10$ \\
Aspirin & $10 \mathrm{mg} / \mathrm{kg}$, i.p. & $20.13 \pm 1.12^{* * *}$ & $71.39 \pm 2.00$
\end{tabular}

Data values shown represent mean \pm SEM $(n=6) .{ }^{* * *} p<0.001$ versus only acetic acid treated group (One-way ANOVA followed by Tukey's Multiple Comparison Test).

leukocytes (PMNs) and assembly of active NADPHoxidase. Presence of Gallic acid in AHM might be contributing to strong anti-inflammatory activity as, O-dihydroxy group of gallic acid is important for the inhibitory activity in vitro [23]. Caffeic acid exerted both in vitro and in vivo anti-inflammatory effects probably through modulation of iNOS expression and other inflammatory mediators. Catechin is the class of flavonoids with potent cancer chemo-preventive, neuro-protective, anti-apoptotic, and anti-inflammatory properties in clinical disorders $[24,25]$. Rutin is an important plant secondary metabolite and reported as hepato-protective, antioxidant, and anti-inflammatory agent [25].

AHE was also found to possess the most significant pharmacological activities, which might be due to the presence of isolated flavanols: 7-O-galloyl catechin, +catechin and methyl gallate, previous data also affirmed that these compounds possess anti inflammatory, analgesic and pain relieving potential [26].

A subcutaneous injection of Brewer's yeast induces pyrexia (called as pathogenic fever) by increasing the production of prostaglandins. Antipyretic activity is commonly mentioned as a characteristic of drugs or compounds which have an inhibitory effect on prostaglandinbiosynthesis and it is considered as a useful test for the screening of plant materials as well as synthetic drugs for their antipyretic potential [1]. AHM and its fraction AHE exhibited significant antipyretic activity at $150 \mathrm{mg} / \mathrm{kg}$ dose, comparable to paracetamol (standard drug). Inhibition of prostaglandin synthesis by blocking the cyclooxygenase enzyme activity could be the possible mechanism of antipyretic action as that of paracetamol. Besides that antipyretic effect might be governed by the ability of extract samples to reduce pro-inflammatory mediators, improve anti-inflammatory signals at sites of injury, or increase antipyretic messages within the brain [27]. The observed effects might be due to the presence of pharmacologically active metabolites that might interfere with the release of prostaglandins. However, it must be noted that several biochemical events occur ultimately to the production of prostaglandins. It may therefore be worthwhile to

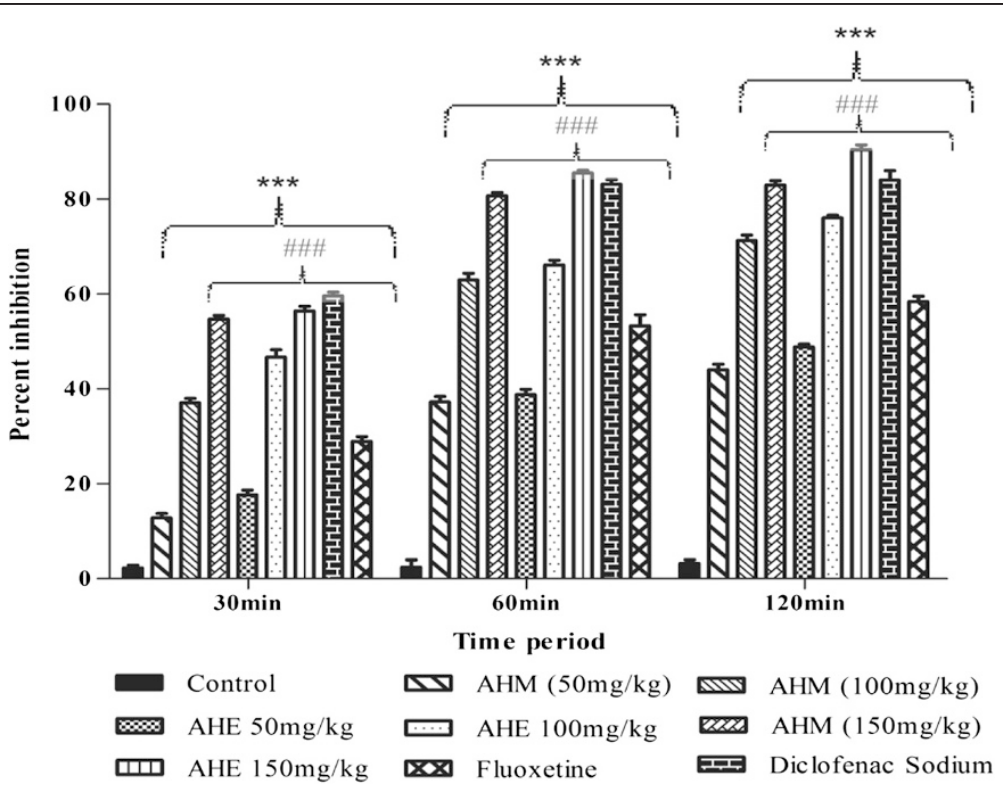

Figure 2 Percent effect of AHM, AHE, diclofenac sodium and fluoxetine in hot plate test. Data analyzed by Two-way ANOVA followed by Bonferroni comparison test. Asterisks ${ }^{* * *}$ indicated statistically significant $(p<0.001)$ values from the control, \#\#\# indicated statistically significant $(p<0.001)$ difference of AHM and AHE (150 mg/kg dose) to fluoxetine. 
Table 5 Effect of AHM and its fraction in hot plate test

\begin{tabular}{|c|c|c|c|c|c|}
\hline \multirow[t]{2}{*}{ Group } & \multirow[t]{2}{*}{ Dose/route } & \multicolumn{4}{|c|}{ Latency time in seconds } \\
\hline & & $0 \mathrm{~min}$ & $30 \mathrm{~min}$ & $60 \mathrm{~min}$ & $120 \mathrm{~min}$ \\
\hline Saline & 10 ml, i.p. & $9.83 \pm 0.601$ & $9.36 \pm 0.317$ & 9.3. \pm 0.881 & $9.167 \pm 0.44$ \\
\hline \multirow[t]{3}{*}{ AHM } & 50 mg/kg, p.o. & $9.61 \pm 0.1675$ & $12.33 \pm 0.881^{* *}$ & $17.00 \pm 0.577^{* * *}$ & $18.33 \pm 0.66^{* * *}$ \\
\hline & 100 mg/kg, p.o. & $9.76 \pm 0.145$ & $17.0 \pm 0.57^{* * *}$ & $22.334 \pm 1.201^{* * *}$ & $24.0 \pm 0.557^{* * *}$ \\
\hline & 150 mg/kg, p.o. & $9.74 \pm 0.52$ & $20.66 \pm 0.881^{* * *}$ & $26.0 \pm 0.577^{* * *}$ & $26.33 \pm 0.334^{* * *}$ \\
\hline \multirow[t]{3}{*}{ AHE } & 50 mg/kg, p.o. & $9.63 \pm 0.185$ & $13.0 \pm 0.577^{* * *}$ & $17.33 \pm 0.667^{* * *}$ & $19.33 \pm 0.333^{* * *}$ \\
\hline & 100 mg/kg, p.o. & $9.83 \pm 0.167$ & $17.66 \pm 0.88^{* * *}$ & $23.0 \pm 0.577^{* * *}$ & $24.33 \pm 0.333^{* * *}$ \\
\hline & 150 mg/kg, p.o. & $9.667 \pm 0.166$ & $22.0 \pm 0.577^{* * *}$ & $26.66 \pm 0.33^{* * *}$ & $27.0 \pm 0.577^{* * *}$ \\
\hline Diclofenac sodium & 10 mg/kg, i.p. & $9.67 \pm 0.667$ & $21.66 \pm 0.88^{* * *}$ & $26.16 \pm 0.89^{* * *}$ & $26.66 \pm 1.00^{* * *}$ \\
\hline Fluoxetine & 10 mg/kg, i.p. & $9.66 \pm 0.881$ & $15.33 \pm 0.334^{* * *}$ & $20.33 \pm 0.90^{* * *}$ & $21.33 \pm 0.667^{* * *}$ \\
\hline
\end{tabular}

Data values shown represent mean \pm SEM $(n=6) .{ }^{* *} p<0.01,{ }^{* * *} p<0.001$ versus saline treated group (Two-way ANOVA followed by Bonferroni multiple comparison test).

investigate the exact point in the biochemical events where the extract exerts its antipyretic effect.

Carrageenan-induced paw edema is an acceptable preliminary screening test for anti-inflammatory activity [28]. Carrageenan induces paw edema bi-phasically: the initial phase extending from $0-2.5 \mathrm{~h}$, predominantly results due to the release of histamine, serotonin and bradykinin. However, COX enzyme is known to play a key role in the development of the later phase of inflammation by converting arachidonic acid into prostaglandins. This enzyme is considered to be identified target for a variety of NSAIDs, such as aspirin and diclofenac sodium, which inhibit rat paw edema at the later phase following carrageenan injection [29-31]. Therefore for comparison three standards were used. AHM significantly $(p<0.001)$ inhibited paw edema in the later phase in a pattern similar to diclofenac sodium, whose mechanism of action is inhibition of cyclooxygenase enzyme synthesis. Although the actual mechanism of action is not known, it is possible that, the anti-inflammatory activity exhibited by $A$. hydaspica extracts could be attributed to the inhibition of the synthesis, release or action of inflammatory mediators. Therefore; we tested AHM and AHE extracts against $\mathrm{PGE}_{2}$ induced paw edema in rats. Results showed that both extracts significantly reduced $\mathrm{PGE}_{2}$ induced edema with maximum protection observed after $4 \mathrm{~h}$. $\mathrm{PGE}_{2}$ is an important mediator of second phase inflammation. These results are in concordance with reported literature for other Acacia species which possesses anti-asthmatic, analgesic, anti-inflammatory, and antioxidant properties [32]. The inhibition of inflammation by extracts could be attributed to the presence of active constituents.

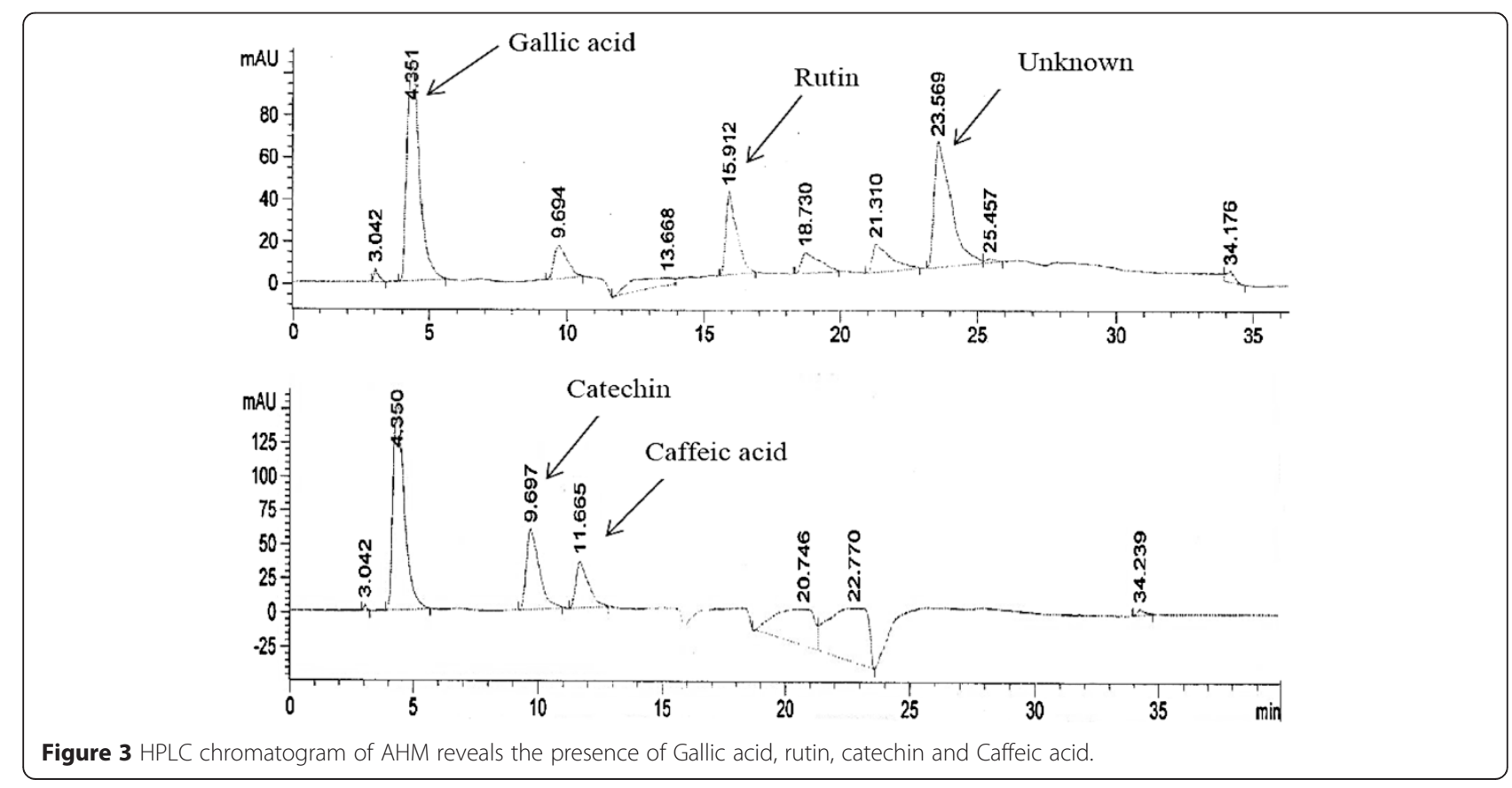


Compound 1 7-O-galloyl catechin (GC)

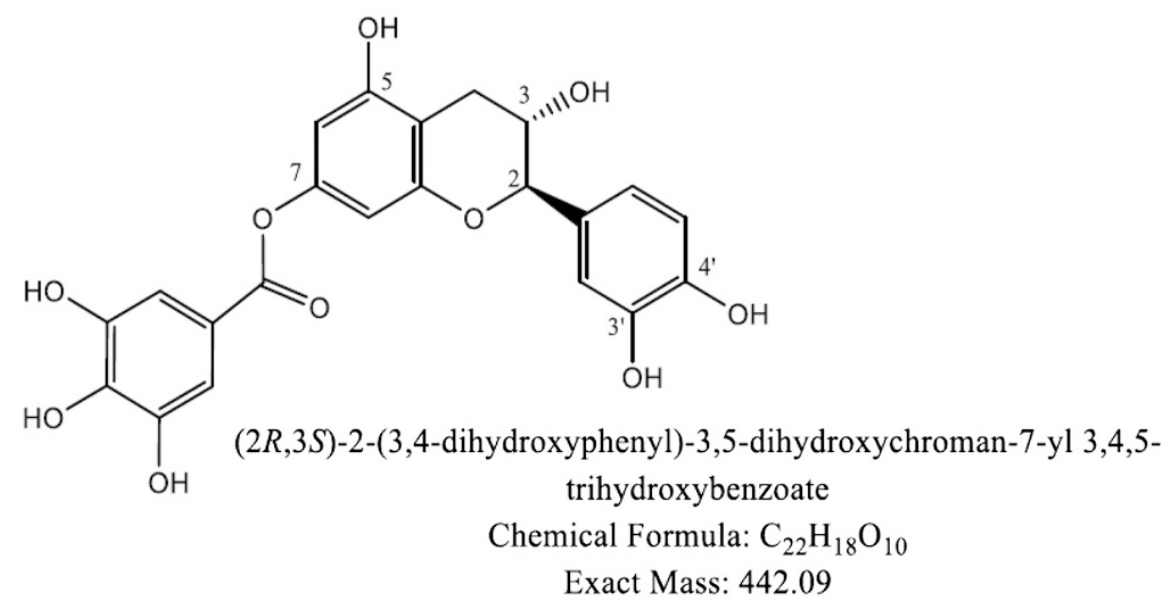

Compound 2 catechin (C)<smiles>Oc1cc(O)c2c(c1)O[C@H](c1ccc(O)c(O)c1)[C@H](O)C2</smiles>

(2R,3S)-2-(3,4-dihydroxyphenyl)chromane-3,5,7-triol

Chemical Formula: $\mathrm{C}_{15} \mathrm{H}_{14} \mathrm{O}_{6}$

Exact Mass: 290.08

Compound 3 methyl gallate (MG)<smiles>COC(=O)c1cc(O)c(O)c(O)c1</smiles>

methyl 3,4,5-trihydroxybenzoate

Chemical Formula: $\mathrm{C}_{8} \mathrm{H}_{8} \mathrm{O}_{5}$

Exact Mass: 184.04

Figure 4 Chemical structures of isolated polyphenols from A. hydaspica ethyl acetate fraction (AHE).

Acetic acid induced writhing test is well proposed method in evaluating the medicinal agents for the analgesic potential. Pain sensation in acetic acid induced writhing paradigm is elicited by producing a localized inflammatory response due to the release of free arachidonic acid from tissue phospholipids via COX, and producing prostaglandins specifically $\mathrm{PGE}_{2}$ and $\mathrm{PGE}_{2} \alpha$, and level of lipoxygenase products may also increase in peritoneal fluid [33-35]. These prostaglandins and lipoxygenase product cause swelling and agony by the cumulative capillary permeability and liberating endogenous substances that stimulate pain nerve endings. NSAIDs cause inhibition of COX enzyme in the peripheral tissues and affect the transduction mechanism of key afferent nociceptors [36]. Our results of acetic acid-induced abdominal constriction assay demonstrated a prominent reduction in writhing reflux. The analgesic effect observed at $150 \mathrm{mg} / \mathrm{kg}$ dose was comparable with the NSAID standard drug diclofenac sodium (Table 4) [37,38]. These findings strongly recommend that $\mathrm{AHM}$ and $\mathrm{AHE}$ 
extracts of A. hydaspica have peripheral analgesic activity and their mechanisms of action may be mediated through inhibition of local peritoneal receptors via cyclooxygenase inhibition.

Thermal nociception models such as hot plat tests were used to evaluate the central analgesic activity. Both AHM and AHE showed significant $(p<0.001)$ analgesic effect in the hot plate test, implicating that plant extract may act as a narcotic analgesic (Table 5). Diclofenac sodium induces analgesic effect through activation of opioid receptors [39], and the apparent similarity between the results of extracts with standard diclofenac sodium, indicates that they might work in a same manner to reduce pain sensation as diclofenac sodium. The profound analgesic activity of $A$. hydaspica extracts might be due to the interference of their active principle (s) with the release of pain mediators, as the flavonoids increase the amount of endogenous serotonin or may interact with 5-HT2A and 5- HT3 receptors which may be involved in the mechanism of central analgesic activity [38]. Diclofenac sodium, fluoxetine $(10 \mathrm{mg} / \mathrm{kg})$ AHM, and AHE $(150 \mathrm{mg} / \mathrm{kg})$ raised the pain threshold level within $30 \mathrm{~min}$ of administration. AHM and AHE showed more pronounced analgesic effect at $150 \mathrm{mg} / \mathrm{kg}$ dose than fluoxetine $(10 \mathrm{mg} / \mathrm{kg})$; stronger effects of plant extracts than fluoxetine, is also in line with a proven concept that medicinal plants possess a combination of constituents, involving different mode (s) of action, offering synergistic effects with no side effects. However the difference in concentrations to achieve the maximum analgesic point could be explained by differences in the metabolic rate of each drug [40].

The presence of gallic acid, methyl gallate, 7-O-galloyl catechin, catechin, rutin and caffeic acid in the other species of the genus Acacia, their effect against COX and 5-lopoxygenase and the antipyretic action of the methanol extract of $A$. modesta leaves [10], supplemented the antipyretic, anti-inflammatory and analgesic activities of our tested extracts and validated its ethnomedicinal use as anti-inflammatory agent.

\section{Conclusion}

To conclude, the methanol extract of $A$. hydaspica aerial parts (AHM) and its derived ethyl acetate fraction (AHE) were evidenced as a natural safe remedy for the treatment of pyrexia, pain and inflammation. Our current findings demonstrated mechanistic evidence for why indigenous people of Pakistan and India found it useful for inflammatory disorders. Interestingly the findings that extracts exhibited both peripheral as well as central analgesic effect provide a rationale for developing opioids alternative which leads to vomiting and nausea. The observed pharmacological activities might have been attributed to the presence of active principles. But there is still need for entailment of identification and acquaintance of molecular targets.
Competing interests

The authors declare that they have no competing interests.

\section{Authors' contributions}

TA made significant contributions to conception, design, experimentation, acquisition and interpretation of data and drafting of the manuscript. MRK has made substantial contributions to analyzing, and revising the manuscript for intellectual content. SR and SU made a contribution into revising and editing the manuscript. BM made contribution to the HPLC experimentation and analysis. All authors read and approved the final manuscript.

\section{Acknowledgment}

We acknowledge Dr. Christine Salomon, Assistant Professor and Assistant Director, Center for Drug Design, University of Minnesota, Minneapolis, MN 55455 for their help in purification of compounds and NMR data interpretation for structure elucidation. Ihsan UI Haq, Department of Pharmacy, Faculty of Biological Sciences, Quaid-i-Azam University, Islamabad 45320, Pakistan, for his help in HPLC-DAD analysis. We are great full to Higher Education Commission (HEC) of Pakistan for providing funding for the research work.

\section{Author details}

${ }^{1}$ Department of Biochemistry, Faculty of Biological Sciences, Quaid-i-Azam University, Islamabad, Pakistan. ${ }^{2}$ Center for Research in Experimental and Applied Medicine, (CREAM), Army Medical College, NUST, Pakistan.

Received: 26 November 2014 Accepted: 20 April 2015

Published online: 29 April 2015

\section{References}

1. Muhammad N, Saeed M, Khan H. Antipyretic, analgesic and anti-inflammatory activity of Viola betonicifolia whole plant. BMC Complement Altern Med. 2012;12(1):59.

2. Sahreen S, Khan MR, Khan RA, Alkreathy HM. Cardioprotective role of leaves extracts of Carissa opaca against CCl4 induced toxicity in rats. BMC Res Notes. 2014;7(1):224.

3. Griffin M, Marie R. Epidemiology of nonsteroidal anti-inflammatory drug-associated gastrointestinal injury. Am J Med. 1998;104(3):23S-9.

4. Cryer B, Duboisø A. The advent of highly selective inhibitors of cyclooxygenase-a review. Prostaglandins Other Lipid Mediat. 1998;56(5):341-61.

5. Vane J, Botting R. New insights into the mode of action of anti-inflammatory drugs. Inflamm Res. 1995:44(1):1-10.

6. Mirjalili M, Tabatabaei S, Hadian J, Ebrahimi SN, Sonboli A. Phenological variation of the essential oil of Artemisia scoparia waldst. et Kit from Iran. J Essent Oil Res. 2007;19(4):326-9.

7. Zargari A. Medicinal plants. Tehran: Tehran University Publications; 1997;1(6):249-65.

8. Chakrabarty T, Gangopadhyay M. The genus Acacia P. Miller (leguminosae: mimosoideae) in India. J Econ Taxon Bot. 1996;20(3):599-633.

9. Adedapo AA, Sofidiya MO, Masika PJ, Afolayan AJ. Anti-inflammatory and analgesic activities of the aqueous extract of acacia Karroo stem bark in experimental animals. Basic Clin Pharmacol Toxicol. 2008;103(5):397-400.

10. Bukhari IA, Khan RA, Gilani AH, Ahmed S, Saeed SA. Analgesic, anti-inflammatory and anti-platelet activities of the methanolic extract of Acacia modesta leaves. Inflammopharmacology. 2010;18(4):187-96.

11. Sokeng SD, Koubé J, Dongmo F, Sonnhaffouo S, Nkono BLNY, Taïwé GS, et al. Acute and chronic anti-inflammatory effects of the aqueous extract of Acacia nilotica (L.) Del. (Fabaceae) pods. Academia J Med Plant. 2013;1(1):01-5.

12. Maldini M, Sosa S, Montoro P, Giangaspero A, Balick M, Pizza C, et al. Screening of the topical anti-inflammatory activity of the bark of Acacia cornigera Willdenow, Byrsonima crassifolia Kunth, Sweetia panamensis Vakovlev and the leaves of Sphagneticola trilobata Hitchcock. J Ethnopharmacol. 2009;122(3):430-3.

13. Mondal S, Raja S, Suresh P, Kumar G. Analgesic, anti-inflammatory and antipyretic properties of Acacia suma stem bark. Int J Phytomed. 2013;5(3):302-7.

14. Dafallah AA. al-Mustafa Z. Investigation of the anti-inflammatory activity of Acacia nilotica and Hibiscus sabdariffa. Am J Chin Med. 1996;24(3-4):263-9.

15. OECD: OECD guideline for testing chemicals 425 . Acute oral toxicity-up and down procedure $2001 ; 2: 12-6$. 
16. Kang JY, Khan MN, Park NH, Cho JY, Lee MC, Fujii H, et al. Antipyretic, analgesic, and anti-inflammatory activities of the seaweed Sargassum fulvellum and Sargassum thunbergii in mice. J Ethnopharmacol. 2008;116(1):187-90.

17. Safaei-Ghomi J, Bamoniri A, Sarafraz MB, Batooli H. Volatile components from Artemisia scoparia Waldst et Kit growing in central Iran. Flavour Fragrance J. 2005;20(6):650-2.

18. Khan H, Saeed M, Gilani AH, Muhammad N, Haq I, Ashraf N, et al. Antipyretic and anticonvulsant activity of Polygonatum verticillatum: comparison of rhizomes and aerial parts. Phytother Res. 2013;27(3):468-71.

19. Singh VP, Jain NK, Kulkarni S. On the antinociceptive effect of fluoxetine, a selective serotonin reuptake inhibitor. Brain Res. 2001;915(2):218-26.

20. Yahagi T, Yakura N, Matsuzaki K, Kitanaka S. Inhibitory effect of chemical constituents from Artemisia scoparia Waldst. et Kit. on triglyceride accumulation in 3 T3-L1 cells and nitric oxide production in RAW 264.7 cells. J Natural Med. 2013;68(2):1-7.

21. El-toumy SA, Mohamed SM, Hassan EM, Mossa A-TH. Phenolic metabolites from Acacia nilotica flowers and evaluation of its free radical scavenging activity. J Am Sci. 2011;7(3):287-95.

22. Yeung HC. Handbook of Chinese herbs and formulas. Los Angeles, CA: Institute of Chinese Medicine; 1985.

23. Han D, Tian M, Row KH. Isolation of four compounds from Herba Artemisiae Scopariae by preparative column HPLC. J Liq Chromatogr Relat Technol. 2009;32(16):2407-16

24. Tan RX, Zheng W, Tang H. Biologically active substances from the genus Artemisia. Planta Med. 1998;64(04):295-302.

25. Shah NA, Khan MR, Naz K, Khan MA. Antioxidant Potential, DNA Protection, and HPLC-DAD Analysis of Neglected Medicinal Jurinea dolomiaea Roots. BioMed Res Int. 2014;2014:726241.

26. Singh R, Akhtar N, Haqqi TM. Green tea polyphenol epigallocatechi3-gallate: Inflammation and Arthritis. Life Sci. 2010;86(25):907-18.

27. Khan MA, Khan H, Tariq SA, Pervez S. Urease Inhibitory Activity of Aerial Parts of Artemisia scoparia: Exploration in an In Vitro Study. Ulcers. 2014:2014:184736.

28. Tian M, Row K. Separation of four bioactive compounds from Herba artemisiae scopariae by HPLC with ionic liquid-based silica column. J Anal Chem. 2011;66(6):580-5.

29. Gilani A-uH, Janbaz KH. Protective effect of Artemisia scoparia extract against acetaminophen-induced hepatotoxicity. Gen Pharmacol Vasc Syst. 1993;24(6):1455-8.

30. Blokhina O, Virolainen E, Fagerstedt KV. Antioxidants, oxidative damage and oxygen deprivation stress: a review. Ann Bot. 2003;91(2):179-94.

31. Birben E, Sahiner UM, Sackesen C, Erzurum S, Kalayci O. Oxidative stress and antioxidant defense. World Allergy Organ J. 2012;5(1):9.

32. Malviya S, Rawat $S$, Kharia A, Verma M. International journal of pharmacy \& life sciences. Int J of Pharm \& Life Sci (IJPLS). 2011;2(6):830-7.

33. Granger DN. Role of xanthine oxidase and granulocytes in ischemiareperfusion injury. Am J Physiol Heart Circ Physiol. 1988;255(6):H1269-75.

34. Duarte I, Nakamura M, Ferreira S. Participation of the sympathetic system in acetic acid-induced writhing in mice. Braz J Med Biol Res. 1987;21(2):341-3.

35. Fenton H. LXXIII.-Oxidation of tartaric acid in presence of iron. Transactions. 1894;65:899-910.

36. Scandalios JG. Genomic responses to oxidative stress. Molecular Medicine: Encyclopedia of Molecular Cell Biology. 2004;5(2):489-512.

37. Zulfiker A, Rahman MM, Hossain MK, Hamid K, Mazumder M, Rana MS. In vivo analgesic activity of ethanolic extracts of two medicinal plants-Scoparia dulcis L. and Ficus racemosa Linn. Biol Med. 2010;2(2):42-8.

38. Kaushik D, Kumar A, Kaushik P, Rana A. Analgesic and Anti-Inflammatory Activity of Pinus roxburghii Sarg. Advances in pharmacological sciences 2012; 2012. Article ID 245431

39. Brogden R, Heel R, Pakes G, Speight TM, Avery G. Diclofenac sodium: a review of its pharmacological properties and therapeutic use in rheumatic diseases and pain of varying origin. Drugs. 1980;20(1):24-48.

40. Gilani AH. Trends in ethnopharmacology. J Ethnopharmacol. 2005;100(1):43-9.

\section{Submit your next manuscript to BioMed Central and take full advantage of:}

- Convenient online submission

- Thorough peer review

- No space constraints or color figure charges

- Immediate publication on acceptance

- Inclusion in PubMed, CAS, Scopus and Google Scholar

- Research which is freely available for redistribution

Submit your manuscript at www.biomedcentral.com/submit 